\title{
Quantifying uncertainties associated with the measurement of primary production
}

\author{
Katharine L. Pemberton, K. Robert Clarke, Ian Joint* \\ Plymouth Marine Laboratory, Prospect Place, The Hoe, Plymouth PL1 3DH, UK
}

\begin{abstract}
Depth-integrated primary production was estimated in the Celtic Sea (European Shelf) by 2 independent methods. Daily production rates were derived from photosynthetic parameters determined by photosynthesis/irradiance $(P / E)$ experiments on samples incubated with ${ }^{14} \mathrm{C}$-bicarbonate $\left({ }^{14} \mathrm{C}\right.$ method) and from in situ profiles with the fast repetitive rate fluorometer (FRRF) method. Production was estimated to be between 332 and $910 \mathrm{mg} \mathrm{C} \mathrm{m}^{-2} \mathrm{~d}^{-1}$ by the ${ }^{14} \mathrm{C}$ method and from 351 to $1278 \mathrm{mg} \mathrm{C} \mathrm{m}^{-2} \mathrm{~d}^{-1}$ by the FRRF method. The uncertainty, or error, of these estimates was determined by calculating $95 \%$ confidence intervals using Taylor series and Monte Carlo modelling approaches. Both approaches revealed significant uncertainty in estimates. The Taylor series analysis of the ${ }^{14} \mathrm{C}$ method indicated that $95 \%$ confidence interval widths were between 4 and $20 \%$ of the estimated production. The smallest error in this study, calculated using a Taylor series analysis, gave a $95 \%$ confidence interval of $(578,622) \mathrm{mg} \mathrm{C} \mathrm{m}^{-2} \mathrm{~d}^{-1}$ for an estimated production rate of $600 \mathrm{mg} \mathrm{C}$ $\mathrm{m}^{-2} \mathrm{~d}^{-1}$. The largest error was calculated using a Monte Carlo analysis and found that a production rate of $377 \mathrm{mg} \mathrm{C} \mathrm{m}^{-2} \mathrm{~d}^{-1}$ had $95 \%$ confidence limits of $(300,453) \mathrm{mg} \mathrm{C} \mathrm{m}^{-2} \mathrm{~d}^{-1}$. Larger uncertainties were associated with the FRRF method, but reflect only the increased complexity of equations used to derive photosynthetic parameters and not a known greater degree of error in the approach. The precision of primary production measurements is a neglected but important factor that should be considered in primary production experiments and in testing satellite remote sensing algorithms.
\end{abstract}

KEY WORDS: Primary production uncertainty $\cdot$ Remote sensing error $\cdot$ Taylor Series $\cdot$ Monte Carlo modelling $\cdot{ }^{14} \mathrm{C} P / E$ curves $\cdot$ Fast repetitive rate fluorometer

\section{INTRODUCTION}

If we are to understand the Earth system, it is important to be able to obtain accurate and precise estimates of the primary productivity of the oceans. The development of satellite ocean colour sensors has made a huge impact on our ability to make global measurements of phytoplankton biomass, and much progress has been made in describing the seasonal progression of phytoplankton biomass in the surface ocean. Different modelling approaches have also allowed primary productivity to be estimated from satellite-derived pigment concentrations (Platt et al. 1990, 1995, Morel 1991, Behrenfeld \& Falkowski 1997) and it has been possible to estimate phytoplankton production on basin (e.g. Joint et al. 2002) and global (e.g. Field et al. 1998) scales. The annual productivity of the marine and ter- restrial systems can now be routinely estimated. Field et al. (1998) estimated global primary productivity to be $105 \mathrm{Pg} \mathrm{C} \mathrm{yr}^{-1}$, with the oceans contributing ca. $45 \mathrm{Pg}$ $\mathrm{C} \mathrm{yr}^{-1}$; this estimate was refined by Behrenfeld et al. (2002) to $41 \mathrm{Pg} \mathrm{C} \mathrm{yr}^{-1}$. However, confidence in these estimates requires that they be validated. The usual approach is to compare with estimates of primary production that are derived by well established methodologies, such as the ${ }^{14} \mathrm{C}$ method.

In 1975, Steemann Nielsen wrote, 'We should not consider measurements of primary production to be correct by more than $\pm 30 \%$ '. If this is true, then we are attempting to calibrate remote-sensing estimates of production with a measurement that may have large unquantified uncertainties. In this paper, we examine the uncertainties associated with 2 commonly applied methods to estimate primary production. These are the 
${ }^{14} \mathrm{C}$ technique - the classic method of determining oceanic productivity that has now been used in more than 35000 oceanographic experiments (Williams \& del Giorgio 2005) - and use of a recently designed instrument for estimating production, the fast repetition rate fluorometer (FRRF, Kolber et al. 1998).

The ${ }^{14} \mathrm{C}$ method involves the estimation of photosynthetic parameters (Jassby \& Platt 1976) from the photosynthesis-light response $(P / E)$ curve. Samples are incubated in a light gradient to determine the maximum specific rate of photosynthesis $\left(P_{\mathrm{m}}^{\mathrm{B}}, \mathrm{mg} \mathrm{C}[\mathrm{mg}\right.$ chlorophyll $]^{-1} \mathrm{~h}^{-1}$ ), the initial slope of the $P / E$ curve $\left.\left(\alpha^{\mathrm{B}}, \mathrm{mg} \mathrm{C}[\mathrm{mg} \mathrm{chl}]^{-1} \mathrm{~h}^{-1} \text { [ } \mathrm{mmol} \text { quanta } \mathrm{m}^{-2} \mathrm{~s}^{-1}\right]^{-1}\right)$ and the derived parameter $E_{k}$ ( $\mu$ mol quanta $\mathrm{m}^{-2} \mathrm{~s}^{-1}$ ). Experiments are usually of short duration (3 to $4 \mathrm{~h}$ ). Daily, depth-integrated production is determined using algorithms that incorporate light attenuation through the water column and photosynthetically active radiation (PAR), measured at the sea surface over the course of the day. The FRRF is a self-contained instrument that allows measurement of photosynthetic parameters in natural phytoplankton assemblages. The ratio of variable fluorescence (the difference between minimum and maximum fluorescence yield) to maximum fluorescence, both measured under ambient irradiance, is used to estimate the photosynthetic quantum yield and the functional absorption cross-section of Photosystem II $\left(\sigma_{\text {PSII }}\right)$. Biomass-specific production rates can be estimated from PAR, $\sigma_{\text {PSII }}$ quantum yield and a knowledge of the size of the photosynthetic unit (Kolber \& Falkowski 1993, Suggett et al. 2001).

All these measurements have associated errors; that is, there is uncertainty around any estimate of primary production that is derived either from the ${ }^{14} \mathrm{C}$ technique or from the FRRF. This variability is difficult to quantify precisely because of the complexity of models of primary production but, in order to establish a level of confidence in production estimates, some estimate of the errors is required. The main sources of uncertainty include errors in the measured values, the effect of integrating parameters over time or space and, most seriously, the ability of a model to accurately describe the process of interest.

In this paper, we examine the uncertainty associated with the estimation of production (specifically, from values of $P_{\mathrm{m}}^{\mathrm{B}}$ and $\alpha^{\mathrm{B}}$, derived by both the ${ }^{14} \mathrm{C}$ technique and the FRRF) and use 2 statistical approaches. The first is a Taylor series. This asymptotic, theoretical approach calculates errors from a polynomial equation that is based on an understanding of the model and of the importance of each parameter in the final production estimate. In the second, a Monte Carlo approach repeatedly calculates production using randomly generated numbers to parameterise the model; the error around the mean of the repeat calculations is an indi- cator of the uncertainty of the model. We acknowledge that other sources of uncertainty, not considered in this study, could lead to appreciable error in a final estimate of primary production. However, an inclusive and thorough understanding of total potential error would require very complex calculations and many of the errors required for such calculations are very difficult or impossible to quantify. In calculating the error associated with a very simple model of primary production, and by including only sources of error associated with measured parameters, we hope to demonstrate how the need to integrate estimates over many hours and many depths results in very large uncertainties around production estimates even when the uncertainties associated with individual parameters are small.

\section{MATERIALS AND METHODS}

Estimates from the Celtic Sea. Measurements of photosynthetic parameters $\left(P_{\mathrm{m}}^{\mathrm{B}}\right.$ and $\left.\alpha^{\mathrm{B}}\right)$ from the ${ }^{14} \mathrm{C}$ and FRRF methods were made in the Celtic Sea during May 2000. We sampled 3 different stations over a 7 d period, and the study has been reported in detail by Pemberton et al. (2004). Briefly, $P / E$ parameters were determined on water samples collected from the surface mixed layer at dawn and incubated with $\mathrm{H}^{14} \mathrm{CO}_{3}{ }^{-}$for 3 to $4 \mathrm{~h}$ in a light gradient incubator that was cooled with surface seawater. The light source was a $12 \mathrm{~V}$ tungsten-halogen lamp with a blue filter to adjust the spectrum to be closer to that of natural light; 15 data points were used for each curve. Carbon fixation rates were normalised to chlorophyll concentration and $P / E$ curves were fitted to the equations of Platt et al. (1980) using SPSS SigmaPlot Version 5.0. In contrast to the data reported in Pemberton et al. (2004) the curve fit used for this study did not include a term for photoinhibition. This change was made because a photoinhibition parameter was not calculated from FRRF data. A Chelsea Instruments FAST-TRACKA FRR fluorometer was used to measure vertical profiles of active fluorescence. For these calculations, data were extracted from 1 cast made in the morning. The instrument was used with an acquisition sequence of 100 saturation flashes, 20 relaxation flashes and $10 \mathrm{~ms}$ sleep time between acquisitions. The parameters determined were minimum and maximum fluorescence in the dark-adapted state $\left(F_{0}\right.$ and $\left.F_{\mathrm{m}}\right)$, maximum fluorescence under ambient light $\left(F_{\mathrm{m}}{ }^{\prime}\right)$ and steady state fluorescence under ambient light $\left(F_{\mathrm{s}}^{\prime}\right)$. The ratio of variable fluorescence, $F_{\mathrm{v}}\left(=F_{\mathrm{m}}-F_{0}\right)$ to $\mathrm{F}_{\mathrm{m}}$, gives an estimate of the maximum photosynthetic quantum efficiency of Photosystem II. The effective photosynthetic quantum efficiency of Photosystem II is calculated as the ratio of $F_{\mathrm{q}}{ }^{\prime}\left(=F_{\mathrm{m}}{ }^{\prime}-F_{\mathrm{s}}{ }^{\prime}\right)$ to $F_{\mathrm{m}}{ }^{\prime}$. Photosynthetic parameters from both techniques were adjusted to account for the 
differences between the in situ light quality and the light sources in the incubator or FRRF. Photosynthetic parameters determined by the ${ }^{14} \mathrm{C}$ method, were adjusted as described in Pemberton et al. (2004). Corrections were made to photosynthetic parameters derived from the FRRF in a similar way, except that the emission spectrum of the FRRF LED was used instead of the emission spectrum of the incubator lamp.

Production derived from $P / E$ parameters from incubations with ${ }^{14} \mathbf{C}$. Primary production was calculated from parameters derived from $P / E$ curves using:

$$
\mathrm{PP}_{z, t}=\left(P_{\mathrm{m}}^{\mathrm{B}}\left[1-\mathrm{e}^{\frac{-\alpha^{\mathrm{B}} \times E_{\mathrm{PAR}_{z, t}}}{P_{\mathrm{m}}^{\mathrm{B}}}}\right]\right) \times[\mathrm{chl}]
$$

$\mathrm{PP}_{z, t}$ is an estimate of depth- and time-specific primary production ( $\mathrm{mg} \mathrm{C} \mathrm{m}^{-2} \mathrm{~h}^{-1}$ ), $E_{\mathrm{PAR}_{z_{1}}}$ is the photosynthetically active radiation ( $\mu$ mol quanta $\mathrm{m}^{-2} \mathrm{~s}^{-1}$ ) at depth $z$ and time $t$ and [chl] is the average chlorophyll a concentration in the water column $\left(\mathrm{mg} \mathrm{m}^{-3}\right)$. The equation assumes that there is no photoinhibition. $E_{\mathrm{PAR}}$ was measured using an ELE DRP-5 PAR sensor mounted high on the ship to avoid shading of the sensor. Data were logged every $30 \mathrm{~s}$ and $E_{\mathrm{PAR}}$ was measured in $\mathrm{W} \mathrm{m} \mathrm{m}^{-2}$. The data were averaged over $30 \mathrm{~min}$ intervals and converted to units of $\mu \mathrm{mol}$ quanta $\mathrm{m}^{-2} \mathrm{~s}^{-1}$ using the equations of Kirk (1994). The attenuation of PAR with depth, $\left(K_{\mathrm{PAR}}\right)$ was calculated as the negative-slope coefficient of the regression against depth of the natural log of $E_{\mathrm{PAR}}$, measured using a Chelsea Instruments PAR meter (downwelling scalar irradiance) attached to the FRRF. The $K_{\text {PAR }}$ value was calculated using data from the morning cast for the surface $30 \mathrm{~m}$. Within this shelf sea region, there was little variability of the slope. Daily, depth-integrated primary production $\left(\mathrm{PP}_{\text {daily }}\right.$ in mg C m${ }^{-2} \mathrm{~d}^{-1}$ ) was calculated by integrating $\mathrm{PP}_{z_{t} t}$ over the day and over the euphotic zone.

The variance associated with a parameter must be known before it can be included in a calculation of the overall error. The standard deviations related to $P_{\mathrm{m}}^{\mathrm{B}}$ and $\alpha^{\mathrm{B}}$ were estimated in the $P / E$ curve fitting procedure using a non-linear (Marquardt-Levenberg) algorithm, and those associated with $K_{\mathrm{PAR}}$ were derived from the linear least squares regression of log PAR against depth. In this study, insufficient replicates were taken for an independent estimation of the errors associated with pigment analysis, but the analytical uncertainty of HPLC pigment analysis in the experimental protocol adopted has been shown to be less than $5 \%$ (Mantoura \& Llewellyn 1983). Consequently, for this analysis of primary production uncertainty, we have assumed that no error was associated with the chlorophyll concentrations determined by HPLC or with the measurement of PAR values at the sea surface. Addition of these sources of error would widen confidence intervals still further (see 'Discussion').
FRRF photosynthetic parameters. Eq. (1) was also used to estimate primary production using photosynthetic parameters derived from FRRF measurements. This provided a direct comparison with the uncertainty determined for the ${ }^{14} \mathrm{C}$ method. Photosynthetic parameters were calculated using data from the light chamber of the FRRF instrument (Eqs. 2 \& 3, adapted from Smyth et al. 2004):

$$
\alpha^{\mathrm{B}}=0.000121 \times \sigma_{\mathrm{PSII}} \times\left[\max \left(\frac{F_{\mathrm{q}}{ }^{\prime}}{F_{\mathrm{m}}{ }^{\prime}}\right) / 0.65\right]
$$

The factor 0.000121 accounts for the conversion of units from mol C $[\mathrm{g} \mathrm{chl}]^{-1} \mathrm{~mol} \mathrm{quanta}^{-1} \mathrm{~m}^{-2}$ to $\mathrm{mg} \mathrm{C}$ [mg $\mathrm{chl}]^{-1} \mathrm{~h}^{-1}$ [ $\mathrm{\mu mol}$ quanta $\left.\mathrm{m}^{-2} \mathrm{~s}^{-1}\right]^{-1}$, the requirement of 8 electrons to evolve 1 molecule of oxygen $\left(\mathrm{O}_{2}\right)$ and a photosynthetic quotient (PQ) value of 1.2. The maximum value of $F_{\mathrm{q}}{ }^{\prime}: F_{\mathrm{m}}{ }^{\prime}$ was chosen to avoid using a value that was quenched by high light.

$$
P_{\mathrm{m}}^{\mathrm{B}}=\alpha^{\mathrm{B}} \times E_{k}
$$

$E_{k}$, the light saturation parameter, was calculated from values of $F_{\mathrm{v}} / F_{\mathrm{m}}$ and $F_{\mathrm{q}}{ }^{\prime} / F_{\mathrm{m}}$ ' fitted to an exponential model (Smyth et al. 2004):

$$
\frac{F_{\mathrm{q}}{ }^{\prime}}{F_{\mathrm{m}}{ }^{\prime}}=A\left(1-\mathrm{e}^{\frac{-E_{\mathrm{PAR}}}{E_{k}}}\right) / E_{\mathrm{PAR}}
$$

where $\mathrm{A}$ is the product $\left(F_{\mathrm{v}} / F_{\mathrm{m}} \times E_{\mathrm{k}}\right)$ and $E_{\mathrm{PAR}}$ was taken from the PAR meter attached to the FRRF. Again the variance associated with each parameter is required for the calculation of error propagation. Photosynthetic parameters from the FRRF are calculated indirectly from fluorescence parameters $F_{\mathrm{q}}{ }^{\prime} / F_{\mathrm{m}}{ }^{\prime}, F_{\mathrm{v}} / F_{\mathrm{m}}$ and $\sigma_{\mathrm{PSII}}$. This means that the error (or standard deviation, SD) associated with derived photosynthetic parameters $\left(\alpha^{\mathrm{B}}\right.$ and $P_{\mathrm{m}}^{\mathrm{B}}$ ) also had to be calculated indirectly from the error on $F_{\mathrm{q}}{ }^{\prime} / F_{\mathrm{m}}{ }^{\prime}$ and $\sigma_{\mathrm{PSII}}$ (Eqs. $5 \& 6$, respectively). The errors associated with $F_{\mathrm{q}}{ }^{\prime} / F_{\mathrm{m}}{ }^{\prime}$ and $\sigma_{\mathrm{PSII}}$ were derived from the variability in the parameter values within the $2 \mathrm{~m}$ depth interval from which the value was taken.

$$
\begin{gathered}
\mathrm{SD} \alpha^{\mathrm{B}}(\mathrm{FRRF})=\alpha^{\mathrm{B}}(\mathrm{FRRF}) \times \sqrt{\left(\frac{\mathrm{SD}^{F_{\mathrm{q}}} / F_{\mathrm{m}}^{\prime}}{F_{\mathrm{q}}^{\prime} / F_{\mathrm{m}^{\prime}}^{\prime}}\right)^{2}+\left(\frac{\mathrm{SD} \sigma_{\mathrm{PSII}}}{\sigma_{\mathrm{PSII}}}\right)^{2}} \\
\mathrm{SD} P_{\mathrm{m}}^{\mathrm{B}}(\mathrm{FRRF})=P_{\mathrm{m}}^{\mathrm{B}}(\mathrm{FRRF}) \times \sqrt{\left(\frac{\mathrm{SD} \alpha^{\mathrm{B}}}{\alpha^{\mathrm{B}}}\right)^{2}+\left(\frac{\mathrm{SD} E_{k}}{E_{k}}\right)^{2}}
\end{gathered}
$$

Development of Taylor series algorithm to calculate error on $\mathbf{P P}$ daily determined by ${ }^{14} \mathbf{C}$ incubations and FRRF. A Taylor series was constructed to determine the variance of the estimated production. The procedure weights the error associated with each individual parameter in the model according to its overall importance in the calculation. This was calculated using partial differentials of the production equation, which can be 
derived and computed to calculate how much change would occur if all parameters except one were held constant. Thus this procedure indicates the extent to which a single parameter influences the result of the overall equation. The process was repeated for all the parameters included in the equation for which error could be calculated (i.e. $\alpha^{\mathrm{B}}, P_{\mathrm{m}}^{\mathrm{B}}$ and $K_{\mathrm{PAR}}$ ). The final part of the analysis was the inclusion of a covariance factor for $\alpha^{\mathrm{B}}$ and $P_{\mathrm{m}}^{\mathrm{B}}$. The estimates of these 2 parameters are known to co-vary, so that high values of $\alpha^{\mathrm{B}}$ co-occur with high values of $P_{\mathrm{m}}^{\mathrm{B}}$ (Behrenfeld et al. 2004). In such cases, correlation between the 2 estimates must be taken into account in the variance calculation. Depending on the form of the function of the parameter estimates whose variance is sought, this covariance factor can either increase or decrease the final variance.

The Taylor series approximation was computed at depth intervals of $1 \mathrm{~m}$ and time intervals of $1 \mathrm{~h}$ to give variance $\mathrm{PP}_{z, t t}$ and these values were integrated throughout the day and euphotic water column depth to calculate the overall variance of daily primary production (variance $\mathrm{PP}_{\text {daily }}$ ). The standard deviation (SD) for the overall model was calculated as the square root of the variance and the $95 \%$ confidence intervals was calculated as $1.96 \times \mathrm{SD}$. The model was written in Matlab Version 7.0.4 and detailed equations are included in Appendix 1.

Development of Monte Carlo models to calculate error on $\mathbf{P P}_{\text {daily }}$ from ${ }^{14} \mathrm{C}$ incubations and FRRF. The Monte Carlo approach is based on repeat calculations of production using randomly generated numbers. Random numbers, of normal distribution and within the expected limits, were generated for those parameters in the model for which the variance had been calculated $\left(\alpha^{\mathrm{B}}, P_{\mathrm{m}}^{\mathrm{B}}\right.$ and $\left.K_{\mathrm{PAR}}\right)$, and primary production was calculated for each group of random numbers. The correlation between estimates of $\alpha^{\mathrm{B}}$ and $P_{\mathrm{m}}^{\mathrm{B}}$ was taken into account in the random number generation procedure. We calculated 100 replicate estimates of production for each depth and time interval, and the standard deviations of the replicate estimates around the mean were assumed to be equal to the error associated with the model. The overall daily error was calculated by integrating these values over depth and over the day. The form of the model is described in Appendix 2.

\section{RESULTS}

\section{Primary production estimated by ${ }^{14} \mathrm{C}$ technique and FRRF}

A series of measurements made in the Celtic Sea in May 2000 has been used to test methods to determine the uncertainty of primary production estimates by both the ${ }^{14} \mathrm{C}$ and the FRRF methods. Fig. 1 shows a typical $P / E$ curve obtained, with low $\mathrm{SD}$ on estimates of $P_{\mathrm{m}}^{\mathrm{B}}$ and $\alpha^{\mathrm{B}}$ (Table 1). The derived photosynthetic parameter values for the FRRF method, as well as station positions, are shown in Table 1.

Values of $P_{\mathrm{m}}^{\mathrm{B}}$ estimated by the 2 methods were similar. The ${ }^{14} \mathrm{C}$ method had a range from 1.36 to $3.39 \mathrm{mg} \mathrm{C}$ $[\mathrm{mg} \mathrm{chl}]^{-1} \mathrm{~h}^{-1}$ and the estimates by the FRRF method were 2.09 to $3.09 \mathrm{mg} \mathrm{C}[\mathrm{mg} \mathrm{chl}]^{-1} \mathrm{~h}^{-1}$. However, there was a consistent difference in the estimates of $\alpha^{\mathrm{B}}$ by the 2 methods. The ${ }^{14} \mathrm{C}$ method had a range from 0.012 to $0.035 \mathrm{mg} \mathrm{C}[\mathrm{mg} \mathrm{chl}]^{-1} \mathrm{~h}^{-1}$ ( $\mu \mathrm{mol}$ quanta $\left.\mathrm{m}^{-2} \mathrm{~s}^{-1}\right)^{-1}$, but the FRRF method showed much less variation, with generally higher values between 0.027 and $0.033 \mathrm{mg} \mathrm{C}$ $[\mathrm{mg} \mathrm{chl}]^{-1} \mathrm{~h}^{-1}$ ( $\mu \mathrm{mol}$ quanta $\left.\mathrm{m}^{-2} \mathrm{~s}^{-1}\right)^{-1}$ (the possible reasons for this are discussed by Smyth et al. 2004). Even without considering any potential errors, the 2 approaches resulted in very different estimates of daily depth-integrated primary production. The minimum production occurred on 27 May and was estimated to be $281 \mathrm{mg} \mathrm{C} \mathrm{m}^{-2} \mathrm{~d}^{-1}$ by the ${ }^{14} \mathrm{C}$ method and $541 \mathrm{mg} \mathrm{C}$ $\mathrm{m}^{-2} \mathrm{~d}^{-1}$ by the FRRF method. There was a smaller difference in the maximum values (1380 and $1309 \mathrm{mg} \mathrm{C}$ $\mathrm{m}^{-2} \mathrm{~d}^{-1}$ respectively) measured on 23 May. The general day-to-day pattern was similar, with production estimates by the 2 methods increasing from Day 1 to Day 2, then showing a general decrease from Day 2 onwards (Fig. 2). Regression analyses of daily production estimates showed a strong correlation between the 2 methods, but consistently higher values from the FRRF approach (slope of symmetric regression of FRRF on ${ }^{14} \mathrm{C}$ data $=1.34, \mathrm{r}^{2}=0.88$ ). It is worth noting that there is a much greater agreement between calculated daily production estimates by the ${ }^{14} \mathrm{C}$ and FRRF approaches than between individual photosynthetic parameters. This is because a large source of the vari-

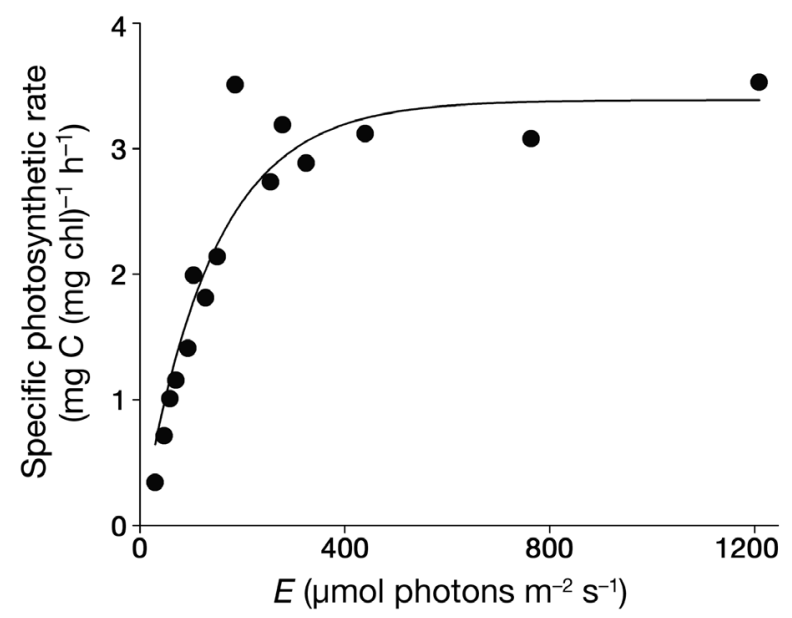

Fig. 1. $P / E$ curve derived from samples taken at dawn in surface mixed layer of the Celtic Sea on 24 May 2000 


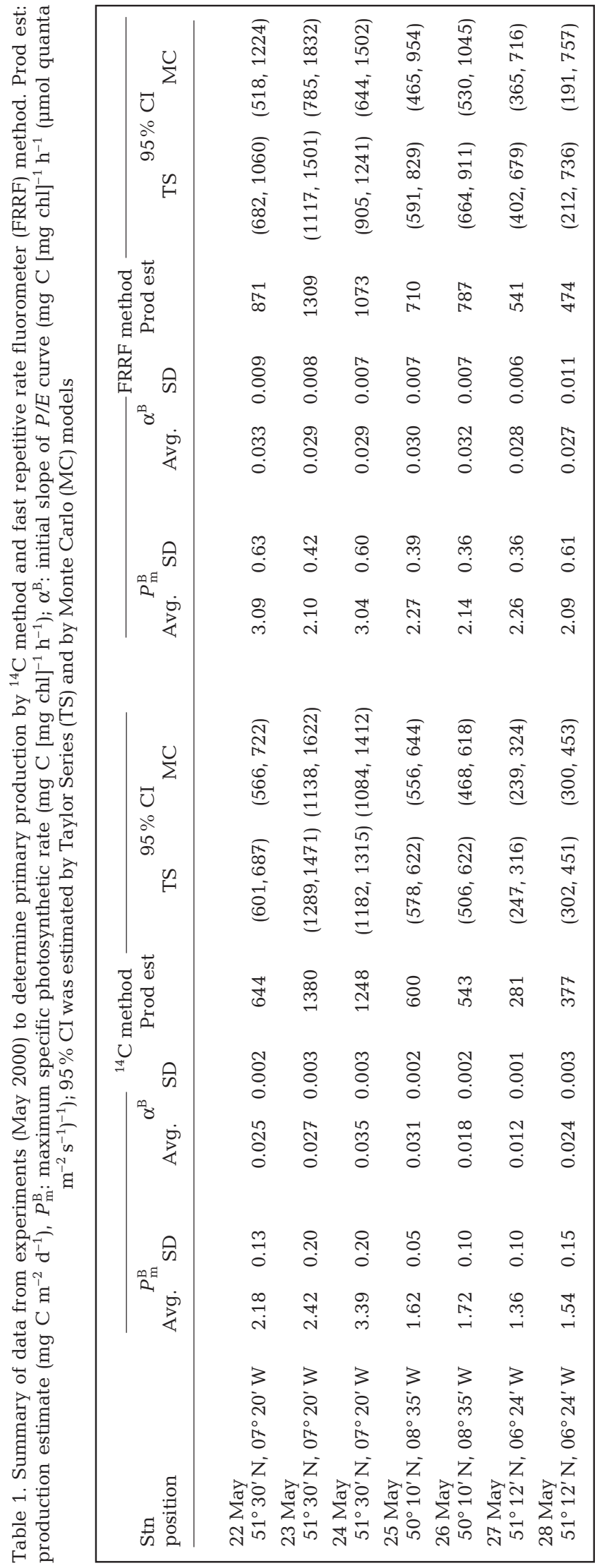

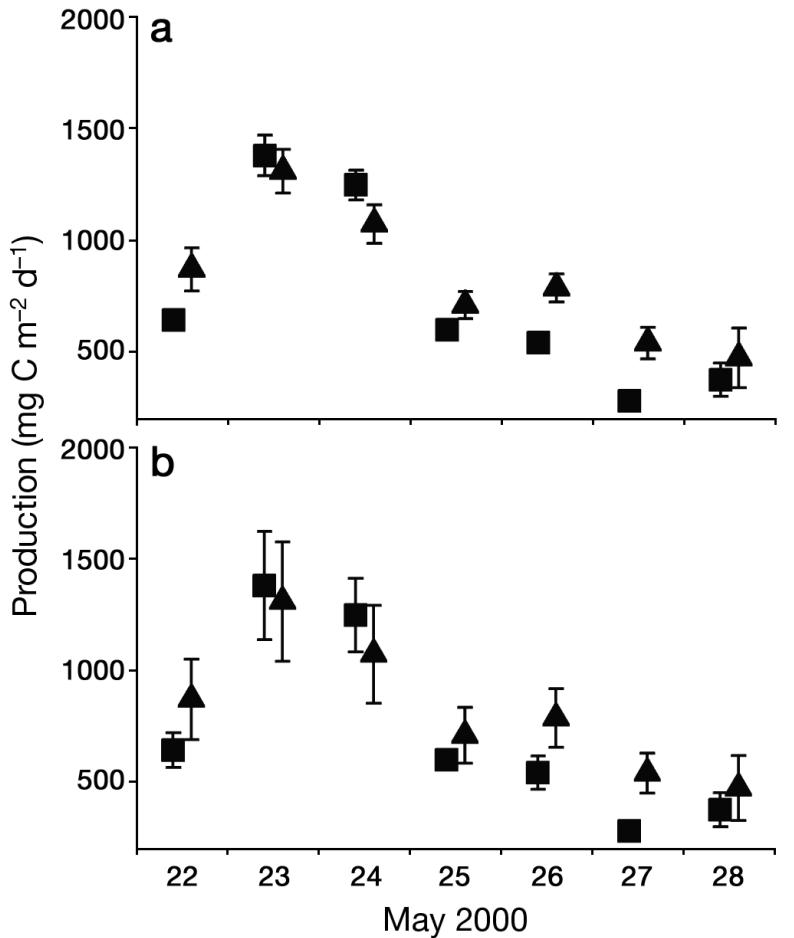

Fig. 2. Estimated production and $95 \%$ confidence intervals for primary production modelled from ${ }^{14} \mathrm{C}(\boldsymbol{\square})$ and FRRF (A) photosynthetic parameters; $95 \%$ confidence intervals calculated using (a) Taylor series approximation and (b) Monte Carlo modelling. To improve clarity, pairs of data points for each day are slightly displaced

ance in production estimates is due to changes in PAR and chlorophyll and values for these parameters are common to the equations used for both the ${ }^{14} \mathrm{C}$ and FRRF approaches. When confidence intervals were included in the plots, the differences between estimates from the ${ }^{14} \mathrm{C}$ and FRRF approaches appears less obvious. The $95 \%$ confidence intervals calculated from the Taylor series (Fig. 2a) for the 2 approaches overlapped for 2 of the 7 dates. For the other dates, estimates from the FRRF were higher than those from ${ }^{14} \mathrm{C}$ in all but 1 case. When Monte Carlo modelling was used, the error bars from the 2 approaches overlapped in all but 2 cases (26 and 27 May), when estimates from the FRRF were again higher than those by the ${ }^{14} \mathrm{C}$ method.

\section{Estimating uncertainty in production estimates}

The 2 methods used in this study to determine the uncertainties associated with production estimates are entirely independent. The Taylor series analysis of the ${ }^{14} \mathrm{C}$ method found that the $95 \%$ confidence interval widths varied from 4 to $20 \%$ of the estimated produc- 
tion (Table 1). The smallest error was calculated for 25 May, when production was estimated to be $600 \mathrm{mg}$ $\mathrm{C} \mathrm{m}^{-2} \mathrm{~d}^{-1}$. However, even with this small error, we cannot say that the true value of production was $600 \mathrm{mg} \mathrm{C}$ $\mathrm{m}^{-2} \mathrm{~d}^{-1}$, only that the interval $(578,622) \mathrm{mg} \mathrm{C} \mathrm{m}^{-2} \mathrm{~d}^{-1}$ probably covers the true value (in $95 \%$ of identical experiments it would have done so). The largest error in ${ }^{14} \mathrm{C}$ estimates $( \pm 20 \%)$ was for 28 May, when the production was calculated to be $377 \mathrm{mg} \mathrm{C} \mathrm{m}^{-2} \mathrm{~d}^{-1}$; in this case, we can state with $95 \%$ confidence that the true value was between 302 and $451 \mathrm{mg} \mathrm{C} \mathrm{m}^{-2} \mathrm{~d}^{-1}$. So the initial production estimation of $377 \mathrm{mg} \mathrm{C} \mathrm{m}^{-2} \mathrm{~d}^{-1}$ does not have the confidence that most researchers place on it, and the true value may be up to $75 \mathrm{mg} \mathrm{C} \mathrm{m}^{-2} \mathrm{~d}^{-1}$ more or less than the initial estimate. There were also significant differences in the measurement of uncertainty given by the 2 approaches to error estimation. The $95 \%$ confidence intervals were usually greater for the Monte Carlo approach than for the Taylor series, although the greatest error was $20 \%$ of primary production (28 May) for both methods. The uncertainties associated with the FRRF method were larger than those of the ${ }^{14} \mathrm{C}$ method. The range of $95 \%$ confidence intervals for the Taylor series varied from \pm 15 to $\pm 55 \%$, and by the Monte Carlo approach from \pm 32 to $\pm 60 \%$. For example, the estimated production on 26 May was $787 \mathrm{mg} \mathrm{C} \mathrm{m}^{-2} \mathrm{~d}^{-1}$; the $95 \%$ CI by the Taylor series was 644 to $911 \mathrm{mg} \mathrm{C} \mathrm{m}^{-2} \mathrm{~d}^{-1}$ and by the Monte Carlo method was 530 to $1045 \mathrm{mg} \mathrm{C} \mathrm{m}^{-2} \mathrm{~d}^{-1}$.

\section{DISCUSSION}

It is common for published values of primary production to quote a single value for primary production estimates and it is rare for the uncertainty associated with that number to be calculated. In one of the few studies that addressed uncertainty, Lewis et al. (1985) used sensitivity analyses to calculate the errors introduced into calculations of areal photosynthesis rate. In a similar approach to that of the present study, they differentiated a simple production equation with respect to $P_{\mathrm{m}}^{\mathrm{B}} \alpha^{\mathrm{B}}$ and $K_{\mathrm{PAR}}$ to determine the effect that errors in each parameter would have on estimates of integral production. They studied the variability in final production estimates introduced by varying 1 parameter at a time. The present study expands on their work by combining the partial differentials of the parameters in a Taylor series, allowing the calculation of confidence intervals on the production estimate when more than 1 parameter varies.

This study has quantified, using Taylor series and Monte Carlo approaches, the considerable uncertainty in the measurement of parameters in estimates of primary production (Fig. 2, Table 1) - in this case, inte- grated over the upper $30 \mathrm{~m}$ of the water column. Uncertainty varies from experiment to experiment, so it is not possible to apply a constant error term to any one methodology. However, in absolute terms, the error estimates are not so variable here as to invalidate standard homogeneity assumptions in an analysis of variance or Student's $t$-test carried out on the resulting average production estimates. For either method, standard deviations varied here by no more than a factor of 2 , usually less. Where such estimates of error can be particularly helpful is in identifying experimental conditions with much larger errors relative to other stations and times, so that these points can be handled differently in subsequent analysis. This might range from (crudely) excluding them to carrying out weighted least squares ANOVAs, regressions etc., which make use of the varying error estimates to down-weight or up-weight each point in relation to the others.

Why does the estimated error vary with the method applied, and which is more appropriate for routine determinations of error? The difference was largely due to the way in which the error from the Taylor series was combined over depth and time, and this led to a lower integrated error than predicted by the Monte Carlo model. The Taylor series calculated depth- and time-specific variance for every metre and every hour and these values were integrated to estimate error for the whole day and water column. This simple integration is a non-conservative approach, as it assumed complete independence of the individual error estimates; this is actually unrealistic because the data are not independent. An assumption of the model is that parameter values (and their standard deviations) remain constant over the course of the day and throughout the whole water column. This means that a high error estimated at one depth is likely to influence the model and result in high error estimates at other depths and times. The magnitude of the error is positively correlated to PAR, decreasing with depth and towards dusk and dawn. Thus, in this study, the Taylor series probably underestimated the daily, depthintegrated error. The Monte Carlo approach does not suffer from such limitations and, assuming that 100 replicate simulations were enough to provide a realistic measure of the range of estimates possible, is expected to provide a better estimate of the confidence intervals around production values.

Some of the large uncertainties associated with the ${ }^{14} \mathrm{C}$ and FRRF based production estimates are due to the way in which we have estimated daily production. Since similar approaches are taken by other researchers to obtain daily estimates of primary production, it is relevant to discuss these limitations. Photosynthetic parameter values used in the analyses were 
measured in the morning and assumed to be constant over the course of the day. This is obviously not realistic and leads to error in the model. However, the model used here was designed to address just such a simple situation in order to demonstrate that the inherent uncertainty associated even with very simple models can be surprisingly large.

The photosynthetic parameters from the FRRF were derived indirectly from $F_{\mathrm{q}}{ }^{\prime}: F_{\mathrm{m}}{ }^{\prime}, F_{\mathrm{v}} / F_{\mathrm{m}}, \sigma_{\mathrm{PSII}}$ and $E_{k}$. As a result, the errors on the FRRF values of $\alpha^{\mathrm{B}}$ and $P_{\mathrm{m}}^{\mathrm{B}}$ had to be derived indirectly from the errors on the original parameters, a calculation that required summing the relative errors from each parameter, and multiplying the sum by the photosynthetic parameter values. This need to combine numerous errors is the probable cause of the high final uncertainty on the FRRF estimates of daily production. In contrast, the errors in the ${ }^{14} \mathrm{C}$ method were derived directly as part of the curve fitting process of estimating $\alpha^{\mathrm{B}}$ and $P_{\mathrm{m}}^{\mathrm{B}}$. It was noted in 'Materials and methods' that in a parallel study, (Pemberton et al. 2004), P/E parameters were calculated using an equation which included a photoinhibition parameter because the curve showed a slightly better fit to most data when photoinhibition was included. In some cases removing photoinhibition led to an increase in the standard error associated with derived parameters, whilst in others the error was decreased.

Lewis et al. (1985) calculated algebraically that when $E_{\mathrm{PAR}(0)}: E_{k}$ is $<4$, the final production estimate is more sensitive to $\alpha^{B}$ and when the value is $>4$, the final production estimate is more sensitive to $P_{\mathrm{m}}^{\mathrm{B}}$. Using this criteria and archived data, they found that under most oceanographic conditions, errors in $\alpha^{\mathrm{B}}$ would have a greater effect than errors in $P_{\mathrm{m}}^{\mathrm{B}}$ on estimates of areal production. Morel et al. (1996) considered the relative roles of parameters in a primary production algorithm and carried out a sensitivity analysis. They compared a model where physiological values were assumed to be constant (in all water types, over the whole water column and throughout the day) with a model in which measured values were used. Their study showed that when either type of model was used, altering $P_{\mathrm{m}}^{\mathrm{B}}$ had a greater effect on final production estimates than altering $\alpha^{\mathrm{B}}$. However, they noted that the results were dependent on the ratio of the 2 parameters (i.e. the value of $E_{k}$ ) and the surface irradiance $\left(E_{\mathrm{PAR}(0)}\right)$. In order to see how well our results supported this theory, sensitivity analyses were carried out by altering $\alpha^{\mathrm{B}}, P_{\mathrm{m}}^{\mathrm{B}}$ and $K_{\mathrm{PAR}}$ by a fixed percentage. We found that when ${ }^{14} \mathrm{C}$ data were used, the results were variable, with alterations in $\alpha^{\mathrm{B}}$ leading to greater changes in areal production estimates in some cases and $P_{\mathrm{m}}^{\mathrm{B}}$ in others. When FRRF data were used, altering $P_{\mathrm{m}}^{\mathrm{B}}$ always had a greater effect than altering $\alpha^{B}$ on production estimates. This is due to the FRRF approach leading to a lower $E_{k}$ value than the ${ }^{14} \mathrm{C}$ approach which, in turn, resulted in $P_{\mathrm{m}}^{\mathrm{B}}$ limiting the rate of photosynthesis at lower light. In support of the work of Lewis et al. (1985), our data show a clear correlation between the percentage of daylight hours where $E_{\mathrm{PAR}(0)}: E_{k}<4$ and the sensitivity of the production model to $\alpha^{\mathrm{B}}$ or $P_{\mathrm{m}}^{\mathrm{B}}$; i.e. an increase in the number of hours, whereby surface $E_{\mathrm{PAR}(0)}: E_{k}>4$ led to an increase in the sensitivity of the model to $P_{\mathrm{m}}^{\mathrm{B}}$.

In their study, Lewis et al. (1985) noted that a large source of error in estimates in $\alpha^{\mathrm{B}}$ was due to spectral differences between ambient light and artificial light in the incubator. In our study, $\alpha^{\mathrm{B}}$ values were spectrally-corrected to minimise this source of error. In order to assess the effect of this correction on predictions of primary production, models were re-run using non-corrected $\alpha^{\mathrm{B}}$ values. Spectral correction led to larger estimates of $\alpha^{\mathrm{B}}$ by the ${ }^{14} \mathrm{C}$ method, with a subsequent increase in primary production of 13 to $19 \%$. In contrast, spectral correction led to a decrease in $\alpha^{\mathrm{B}}$ by the FRRF and a subsequent decrease in primary production of 14 to $21 \%$. Without this correction the difference between estimates from the 2 approaches would therefore have been much greater.

It is important to emphasise that the errors calculated here do not tell us anything about how well the chosen models actually describe the relationship between primary production and PAR. The errors reflect only the standard deviations of the parameter values. In this study, we have assumed that the measurements of surface PAR and chlorophyll are entirely error-free. In reality, there are uncertainties in these and other measurements that should be incorporated into an overall assessment of confidence. From a practical point of view, comparing $E_{\mathrm{PAR}(0)}$ with $E_{k}$ gives a good indication of which parameters are likely to have the greatest effect on primary production estimates. Improvements in our ability to correct for spectral differences between artificial and ambient light should also improve estimates of photosynthetic parameters. Absorption due to non-photosynthetic pigments was not taken into account in this study but could help improve future estimates of the phytoplankton absorption spectrum (Lewis et al. 1985).

The high degree of uncertainty in primary production estimates has important implications for the estimation of production by satellite remote sensing. Algorithms to estimate production from biomass are poorly calibrated, there are uncertainties in converting waterleaving radiance into pigment concentration, and there are difficulties in dealing with cloud cover. Some attempts have been made to quantify the uncertainties related to satellite-derived production estimates. For example, Joint \& Groom (2000) attempted to place limits on the uncertainty of a simple regression of 
surface chlorophyll with depth-integrated production, based on $24 \mathrm{~h}$ in situ incubations. The regression had a reasonably high explained variance $\left(r^{2}=0.75\right)$, but when the prediction intervals were calculated, there was a large spread in predicted values of production. With a mean value for predicted production of $\sim 0.6 \mathrm{~g} \mathrm{C}$ $\mathrm{m}^{-2} \mathrm{~d}^{-1}$, and assuming that there was no error at all in the estimation of chlorophyll concentration, the $95 \%$ prediction intervals were 0.33 and $1.1 \mathrm{~g} \mathrm{C} \mathrm{m}^{-2} \mathrm{~d}^{-1}$. It is worth emphasising that these wide prediction limits from this empirical satellite algorithm were obtained by assuming perfect chlorophyll retrieval from SeaWiFS images (Joint \& Groom 2000). This is an example of the uncertainties associated with the use of the simplest possible algorithm to determine production and does not consider the uncertainties associated with more complex algorithms to estimate production (e.g. Morel 1991). Biomass retrieval is considered to be the largest source of error in satellite production models (Platt et al. 1995, Joint \& Groom 2000). The design specification of the SeaWiFS sensor anticipated retrieval of chlorophyll concentrations for Case I waters to within $\pm 35 \%$ of real values (Hooker \& McClain 2000). This high uncertainty may propagate errors through the process of estimating production from satellite remote sensing.

Added to these uncertainties, we believe that more consideration should be given to determining the actual precision of primary production estimates that are used for ground-truthing. It is important that an understanding is developed of the limitations of primary production estimates and that it is made clear which sources of error are included or excluded from any calculation.

Acknowledgements. This study was partly funded by the UK Natural Environment Research Council through the Plymouth Marine Laboratory core strategic research programme and by the EU Commission project PROOF (CEC contract number EVK3-CT-1999-00019). K.P. thanks the Zoological Museum of the University of Zurich for access to facilities whilst writing this paper.

\section{LITERATURE CITED}

Behrenfeld MJ, Falkowski PG (1997) Photosynthetic rates derived from satellite-based chlorophyll concentration. Limnol Oceanogr 42:1-20

Behrenfeld MJ, Esaias WE, Turpie KR (2002) Assessment of primary production at the global scale. In: Williams PJ LeB, Thomas DN, Reynolds CS (eds) Phytoplankton productivity: carbon assimilation in marine and freshwater ecosystems. Blackwell Science, Oxford, p 156-186

Behrenfeld MJ, Prasil O, Babin M, Bruyant F (2004) In search of a physiological basis for covariations in light-limited and light-saturated photosynthesis. J Phycol 40:4-25

Field CB, Behrenfeld MJ, Randerson JT, Falkowski PG (1998) Primary production of the biosphere: integrating terrestrial and oceanic components. Science 281:237-240

Hooker SB, McClain CR (2000) The calibration and validation of SeaWiFS data.. Prog Oceanogr 45:427-465

Jassby AD, Platt T (1976) Mathematical formulation of the relationship between photosynthesis and light for phytoplankton. Limnol Oceanogr 21:540-547

Joint I, Groom SB (2000) Estimation of phytoplankton production from space, current status and future potential of satellite remote sensing. J Exp Mar Biol Ecol 250:233-255

Joint I, Groom S, Chou L, Wollast R, Tilstone GH, Figueiras FG, Loijens M, Smyth TJ (2002) The response of phytoplankton production to periodic upwelling and relaxation events at the Iberian shelf break: estimates by the ${ }^{14} \mathrm{C}$ method and by satellite remote sensing. J Mar Syst 32: 219-238

Kirk JTO (1994) Light and photosynthesis in aquatic ecosystems, 2nd edn. Cambridge University Press, Cambridge

Kolber Z, Falkowski PG (1993) Use of active fluorescence to estimate phytoplankton photosynthesis in situ. Limnol Oceanogr 38:1646-1665

Kolber ZS, Prasil O, Falkowski PG (1998) Measurements of variable chlorophyll fluorescence using fast repetition rate techniques: defining methodology of experimental protocols. Biochim Biophys Acta 1367:88-106

Lewis MR, Warnock RE, Platt T (1985) Absorption and photosynthetic action spectra for natural phytoplankton populations: implications for production in the open ocean. Limnol Oceanogr 30:794-806

Mantoura RFC, Llewellyn CA (1983) The rapid determination of algal chlorophyll and carotenoid pigments and their breakdown products in natural waters by reverse-phase high-performance liquid chromatography. Anal Chim Acta 151:297-314

Morel A (1991) Light and marine photosynthesis - a spectral model with geochemical and climatological implications. Prog Oceanogr 26:263-306

Morel A, Antoine D, Babin M, Dandonneau Y (1996) Measured and modelled primary production in the northeast Atlantic (EUMELI JGOFS program): the impact of natural variations in photosynthetic parameters on model predictive skill. Deep-Sea Res I 43:1273-1304

Pemberton K, Rees AP, Miller PI, Raine R, Joint I (2004) The influence of water mass characteristics on phytoplankton diversity and production in the Celtic Sea. Cont Shelf Res 24:2011-2028

Platt T, Gallegos CL, Harrison WG (1980) Photoinhibition of photosynthesis in natural assemblages of marine phytoplankton. J Mar Res 38:687-701

Platt T, Sathyendranath S, Ravindran P (1990) Primary production by phytoplankton - analytic solutions for daily rates per unit area of water surface. Proc R Soc Lond Ser B 241:101-111

Platt T, Sathyendranath S, Longhurst A (1995) Remote sensing of primary production in the oceans: promise and fulfilment. Philos Trans R Soc Lond Ser B 348:191-202

Smyth TJ, Pemberton KL, Aiken J, Geider RJ (2004) A methodology to determine primary production and phytoplankton photosynthetic parameters from fast repetition rate fluorometry. J Plankton Res 26:1337-1350

Steemann Nielsen E (1975) Marine photosynthesis: with special emphasis on the ecological aspects. Elsevier, Amsterdam

Suggett D, Kaay G, Holligan P, Davey M, Aiken J, Geider R (2001) Assessment of photosynthesis in a cyanobacterial bloom by use of fast repetition rate fluorometer. Limnol Oceanogr 46:802-810

Williams PJLeB, del Giorgio PA (2005) Respiration in aquatic ecosystems: history and background. In: del Giorgio PA, Williams PJ LeB (eds) Respiration in aquatic ecosystems. Oxford University Press, Oxford, p 1-17 
Appendix 1. Equations used to quantify the error associated with primary production based on a Taylor series approximation

Total variance (Variance $\mathrm{PP}_{\text {daily }}$ ) was calculated according to Eqs. (A1.1) to (A1.3):

$$
\begin{gathered}
\text { Variance } \mathrm{PP}_{\text {daily }}=\int_{0}^{D} \int_{0}^{Z_{e}} \text { Variance } \mathrm{PP}_{z, t} \\
\text { Variance } \mathrm{PP}_{z, t}=\sum_{n=1}^{N}\left[\left(\frac{\partial \mathrm{PP}_{z, t}}{\partial n}\right)^{2} \times \text { Variance }(n)\right]+\text { Covariance factor }
\end{gathered}
$$

where $n$ is the ' $n$ th' parameter in the production model.

$$
\text { Covariance factor }=\sum_{n 1} \sum_{n 2}\left[\left(\frac{\partial \mathrm{PP}_{z, t}}{\partial n 1}\right) \times\left(\frac{\partial \mathrm{PP}_{z, t}}{\partial n 2}\right) \times \operatorname{Cov}(n 1, n 2)\right]
$$

In order to simplify the expression of the differentials of the production equation, it is convenient to define 2 terms A and B as:

$$
\begin{gathered}
A=\exp \left[\left(-\frac{\alpha^{\mathrm{B}}}{P_{\mathrm{m}}^{\mathrm{B}}}\right) \times \mathrm{PAR}_{0} \times \mathrm{e}^{-K_{\mathrm{PAR}} Z}\right] \\
B=\mathrm{PAR}_{0} \times \mathrm{e}^{-K_{\mathrm{PAR}} Z}
\end{gathered}
$$

The specific production equation could then be described as:

$$
\mathrm{PP}_{z, t}=P_{\mathrm{m}}^{\mathrm{B}}(1-A)
$$

The partial differentials of this equation with respect to the parameters $P_{\mathrm{m}}^{\mathrm{B}} \alpha^{\mathrm{B}}$, and $K_{\mathrm{PAR}}$ are as follows:

$$
\begin{gathered}
\frac{\partial \mathrm{PP}_{z, t}}{\partial P_{\mathrm{m}}^{\mathrm{B}}}=(1-A)-\frac{A \alpha^{\mathrm{B}} B}{P_{\mathrm{m}}^{\mathrm{B}}} \\
\frac{\partial \mathrm{PP}_{z, t}}{\partial \alpha^{\mathrm{B}}}=B A \\
\frac{\partial \mathrm{PP}_{z, t}}{\partial K_{\mathrm{PAR}}}=-A B \alpha^{\mathrm{B}} z
\end{gathered}
$$

Eqs. (A1.10) and (A1.11) show the form of the Covariance factor and the equation used to calculate the Covariance (Cov) between $P_{\mathrm{m}}^{\mathrm{B}}$ and $\alpha^{\mathrm{B}}$ respectively. (The covariances between $P_{\mathrm{m}}^{\mathrm{B}}$ and $K_{\mathrm{PAR}}$, and $\alpha^{\mathrm{B}}$ and $K_{\mathrm{PAR}}$ estimates are taken to be zero).

$$
\text { Covariance factor }=\left[2 \times \operatorname{Cov}\left(P_{\mathrm{m}}^{\mathrm{B}}, \alpha^{\mathrm{B}}\right) \frac{\partial P}{\partial P_{\mathrm{m}}^{\mathrm{B}}} \times \frac{\partial P}{\partial \alpha^{\mathrm{B}}}\right]
$$
where:

$$
\operatorname{Cov}\left(P_{\mathrm{m}}^{\mathrm{B}}, \alpha^{\mathrm{B}}\right)=\operatorname{correlation}\left(P_{\mathrm{m}}^{\mathrm{B}}, \alpha^{\mathrm{B}}\right) \times \mathrm{SD} P_{\mathrm{m}}^{\mathrm{B}} \times \mathrm{SD} \alpha^{\mathrm{B}}
$$

Appendix 2. Equations used to quantify the error associated with primary production using Monte Carlo modelling

Normally distributed random numbers, with mean of 0 and standard deviation of 1 , were generated using an in-built IDL function (RANDOMN), which is based on the BoxMuller method. These numbers are referred to as $x 1, x 2$ and $\mathrm{x} 3$ and are used to generate the 3 values $P_{\mathrm{m}}^{\mathrm{B}}, \alpha^{\mathrm{B}}$ and $K_{\mathrm{PAR}}$. The correlation between $P_{\mathrm{m}}^{\mathrm{B}}$ and $\alpha^{\mathrm{B}}$ was included by converting $x 1$ and $x 2$ to a pair of correlated normal variables, $y 1$ and $y 2$, according to:

$$
\begin{gathered}
y 1=x 1 \\
y 2=\rho \times x 1+\left(\sqrt{1-\rho^{2}}\right) \times x 2
\end{gathered}
$$

where $\rho$ is the correlation between $P_{\mathrm{m}}^{\mathrm{B}}$ and $\alpha^{\mathrm{B}}$. $K_{\mathrm{PAR}}$ was not correlated to the other variables, so $x 3$ was used in subsequent calculations. Finally, $y 1, y 2$ and $x 3$ were converted to the random numbers for use in the model by an adjustment to make the mean and standard deviation fall in the expected range, as shown below:

$$
\begin{gathered}
r P_{\mathrm{m}}^{\mathrm{B}}=\mu\left(P_{\mathrm{m}}^{\mathrm{B}}\right)+\mathrm{SD}\left(P_{\mathrm{m}}^{\mathrm{B}}\right) \times y 1 \\
r \alpha^{\mathrm{B}}=\mu\left(\alpha^{\mathrm{B}}\right)+\mathrm{SD}\left(\alpha^{\mathrm{B}}\right) \times y 2 \\
r K_{\mathrm{PAR}}=\mu\left(K_{\mathrm{PAR}}\right)+\mathrm{SD}\left(K_{\mathrm{PAR}}\right) \times x 3
\end{gathered}
$$

$r P_{\mathrm{m}}^{\mathrm{B}}, r \alpha^{\mathrm{B}}$ and $r K_{\mathrm{PAR}}$ refer to the random estimates of $P_{\mathrm{m}}^{\mathrm{B}}, \alpha^{\mathrm{B}}$ and $K_{\mathrm{PAR}}$ respectively, and the parameter values on the right hand side of the equation relate to the measured means $(\mu)$ and standard deviations (SD). 